\title{
Sources and pathways of trace elements in urban environments: a multi-elemental qualitative approach
}

\author{
E. De Miguel*, J.F. Llamas, E. Chacón, L.F. Mazadiego \\ Grupo de Geoquímica Ambiental, E.T.S. Ingenieros de Minas Madrid-Ríos Rosas 21, E-28003 Madrid, Spain
}

\begin{abstract}
A geochemical model of an urban environment is presented in which multielemental tracers are used to characterise the circulation of trace elements in particulate matter (atmospheric aerosol, street dust and urban soil) within a city.
\end{abstract}

Keywords: Trace elements; Urban; Cycles; Street dust; Soil; Suspended particles

Urban environments can be geochemically modelled in the same way as natural environments if they are considered to consist of different, interrelated spheres, i.e. soil, street dust and suspended particles, among which particulate matter circulates. In this process, the composition of the particles generated in urban or natural sources undergoes geochemical changes before these particles finally accumulate in 'sinks' within or outside the city limits.

In order to evaluate the amount of trace elements in each urban sphere and the rate of mass transfer among them a simplified, qualitative model must first be put forward. The results from

\footnotetext{
* Corresponding author. Tel.: +34-91-336-6992; fax: + 3491-336-7068.

E-mail address: edemiguel@qyc.upm.es (E. De Miguel)
}

several research projects carried out in Spain, Norway, and the Czech Republic between 1990 and 1997 have been used to outline a geochemical model of urban environments that focuses on the circulation of particulate material in the city (Fig. 1). Three types of particulate material have been considered: suspended particles (size fractions $<2.5 \mu \mathrm{m}$ and $2.5-10 \mu \mathrm{m}$ ), settled particles or street dust (size fraction $<100 \mu \mathrm{m}$ ), and soil particles (size fraction $<100 \mu \mathrm{m}$ ). All samples were acid-digested and analysed either by ICP-MS or by ICP-AES.

At the core of the model lies the complex set of physical processes (deposition-resuspensionsurface creep/saltation, aqueous transport) through which particles are transferred from one geochemical sphere to another. The size fraction $<100 \mu \mathrm{m}$ is selected because particles with aero- 


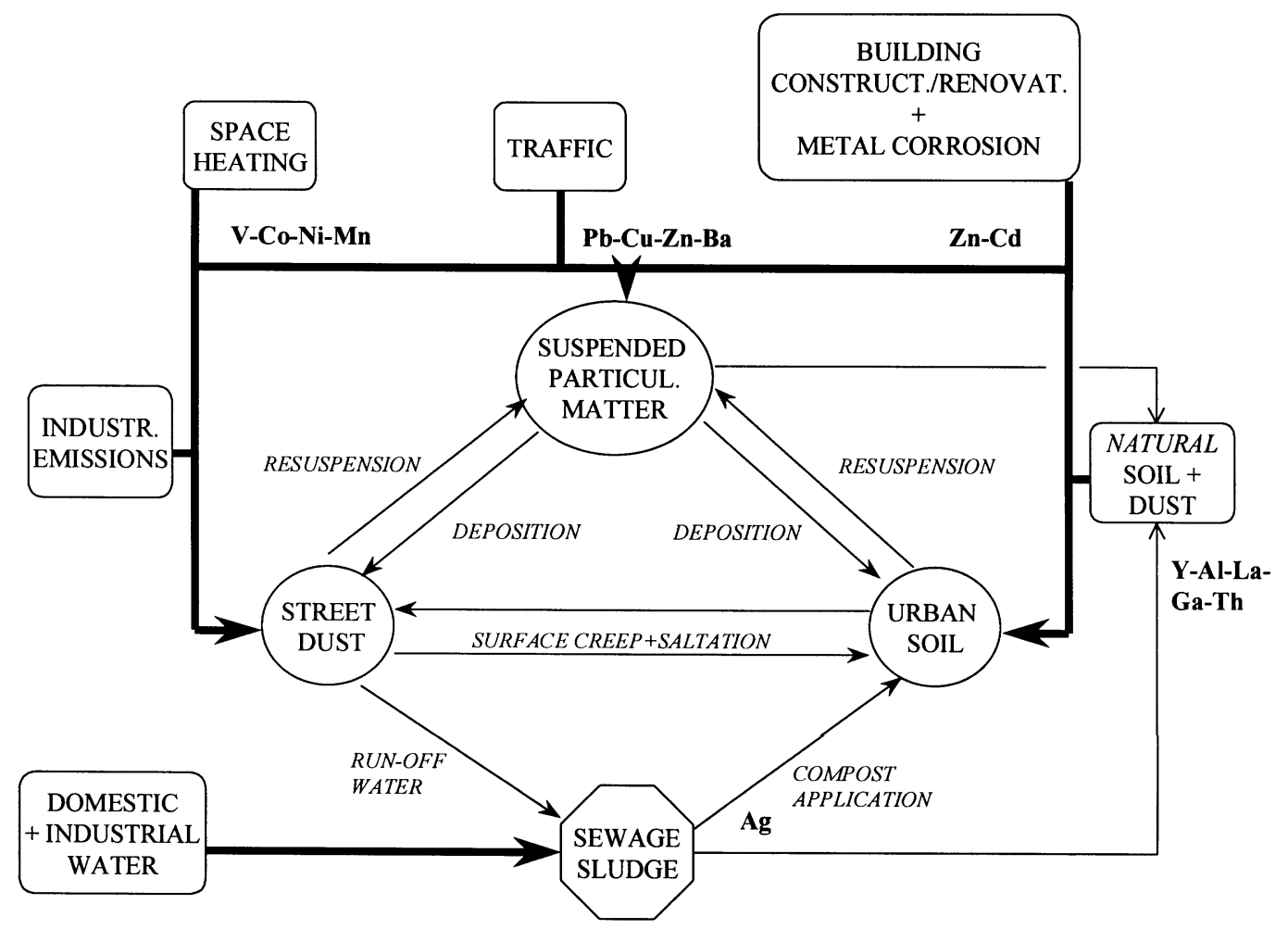

Fig. 1. Schematic model of the urban cycle of particulate material.

dynamic diameters $<100 \mu \mathrm{m}$ can be transported by suspension (as opposed to 'saltation' or 'creep' for larger particles) and the finest among them $(<10 \mu \mathrm{m})$ are easily incorporated into the urban aerosol (Sehmel, 1980; Nicholson, 1988).

The influence of the different sources of trace elements considered in this model and the various geochemical cycles that take place in urban environments can seldom be traced with a single element. One of the few examples in which this is possible involves the use of $\mathrm{Ag}$ as a tracer of composted sewage sludge as amendment in urban soils. The concentration of $\mathrm{Ag}$ can thus be used to evaluate the contribution of compost application to the trace element contents of these soils.

More commonly, multielemental tracers will be required to adequately characterise the influence of the different sources of trace elements and the exchange of particulate material between the different urban spheres. Multivariate statistical techniques (i.e. Principal Component Analysis, Factor
Analysis, Cluster Analysis, Discriminant Analysis, etc.) are valuable tools in this effort (Davies and Wixson, 1987; Sánchez Gómez and Ramos Martín, 1987; Harrison et al., 1997). In simple urban environments or in small sectors within a city, the association $\mathrm{Pb}-\mathrm{Cu}-\mathrm{Zn}-\mathrm{Ba}$ can be used to evaluate the contribution of traffic more reliably than the concentration of $\mathrm{Pb}$ alone, $\mathrm{Zn}-\mathrm{Cd}$ reveals the influence of the corrosion of building materials, and the combination of $\mathrm{V}-\mathrm{Ni}-\mathrm{Mn}-\mathrm{Co}$ can be linked to emissions from domestic heating systems.

In many instances, however, the complexity of urban environments is such that it is impossible to distinguish the influence of single sources of trace elements or characterise single cycles, even with multielemental tracers. On these occasions, often encountered in cities subjected to strong and diverse industrial emissions, a multielemental approach will only reveal the broad categories of elements present in each urban sphere, i.e. 'natu- 
ral', 'industrial', 'urban', and 'mixed/altered', and the effect of some fundamental geochemical processes, like the relationship between oxidation potential and solubility. The 'natural' component of the urban particulate material is especially well defined by the association $\mathrm{Y}-\mathrm{Al}-\mathrm{Ga}-\mathrm{La}-\mathrm{Th}$ and remains fairly constant in all the spheres (soil, street dust and suspended particles) and in different cities. The separation of $U$ from $T h$, due to the different solubility of the compounds of $\mathrm{U}^{6+}$ and $\mathrm{Th}^{4+}$, illustrates the differentiation of 'altered' elements after they leave their original sources. Lastly, the combination $\mathrm{Cu}-\mathrm{Pb}-\mathrm{Zn}$ ('urban' elements) is the best multielemental tracer of the influence of an urban environment, as a whole, on the composition of the natural particulate material found outside its limits.

\section{References}

Davies BE, Wixson BG. Use of factor analysis to differentiate pollutants from other trace metals in surface soils of the mineralised area of Madison County, Missouri, USA. Water Air Soil Pollut 1987;33:339-348.

Harrison RM, Smith DJT, Pio CA, Castro LM. Comparative receptor modelling study of airborne particulate pollutants in Birmingham (United Kingdom), Coimbra (Portugal) and Lahore (Pakistan). Atmos Environ 1997;31:3309-3321.

Nicholson KW. A review of particle resuspension. Atmos Environ 1988;22:2639-2651.

Sánchez Gómez ML, Ramos Martín MC. Application of cluster analysis to identify sources of airborne particles. Atmos Environ 1987;21:1521-1527.

Sehmel GA. Particle resuspension: a review. Environ Int 1980;4:107-127. 